\title{
Resumen / Diseño experimental: Una utopía posible
}

A pesar de que la Ciencia -ese Saber sin Sujeto- no siempre fue experimental y aunque no todas las ciencias pueden serlo, la experimentación de ha convertido en el estandarte que distingue a la Ciencia de todas las demas formas de conocimiento y con el cual legítima su pretensión de encarnar el saber "verdadero".

Conforme las Ciencias, en particular las ciencias físicas y naturales, se van profesionalizando, burocratizando y mercantilizando, las Artes se postulan como un espacio con mayor libertad y disponibilidad para la experimentación. El Diseño moderno -en el sentido mas amplio del término-, siempre a medio camino entre el método racional y la intuición artística, en tanto saber práctico al servicio de la producción de mercancías y servicios, parece desprovisto de vocación experimental.

¿Qué condiciones -institucionales, materiales y subjetivas- debería darse para que el Diseño pueda desplegar esa reprimida pulsión experimentadora? En otras palabras, ¿Qué hacer para que la práctica experimental en las disciplinas proyectuales sea posible?

\section{Palabras clave}

Disciplinas proyectuales - Diseño - diseño experimental - intuición artística - método racional - práctica experimental.

\section{Summary / Experimental Design: A possible utopia}

In spite of the fact that Science -as a Know without Subject- wasn $t$ always experimental and although not all the sciences can be, the experimentation has become the banner that distinguishes the Science of all the others forms of knowledgement and with which legitimate the pretension of the "true" knowledge

As the Sciences, particularly the natural and physical ones, has been professionalized, bureaucratized and marketized, the Arts are becoming spaces with freedom and experimentation availability.

The modern Design - in the extensive sense of the term-, has always been between the rational method and the artistic intuition; as a practical knowledge used for the production of merchandise and services, the design seems lacking experimental vocation.

What conditions -institutionals, materials and subjectives- should be given to make the Design able to reveal its experimentation skills? In other words, what can we do to make possible the experimental practice in the project disciplines?

\section{Key words}

Artistic intuition - client - Design - experimental design - practical knowledge - project disciplines - rational method.

\section{Resumo / Eperimental: Uma utopia possível}

A pesar de que a Ciência -esse Saber sem Sujeito- não sempre foi experimental e embora nem todas as ciências possam sê-lo, a experimentação ha se convertido no estandarte que distingue à Ciência de todas as outras formas de conhecimento e com a qual legitima sua pretensão de encarnar o saber "verdadeiro".

Conforme as Ciências, em particular as ciências físicas e naturais, vão-se profissionalizando, burocratizando e mercantilizando, as Artes se postulam como um espaço com maior liberdade e disponibilidade para a experimentação. O Design moderno -no sentido mais amplo do termo -, sempre na metade do caminho entre o método racional e a intuição artística, em tanto saber prático ao serviço da produção de mercancias e serviços, parece desprovido de vocação experimental.

¿Quê condições -institucionais, materiais e subjetivas- deveria dar-se para que o Design possa desenvolver essa reprimida pulsão experimentadora? Em outras palavras, ¿o quê fazer para que a prática experimental nas disciplinas projetais sejam possíveis?

\section{Palabras chave}

Design - design experimental - disciplinas projetais - método racional - prática experimental - pulsão experimentadora.

Cuadernos del Centro de Estudios en Diseño y Comunicación [Ensayos], № 23 (2007). pp 55-72. ISSN 1668-0227

\footnotetext{
* Gustavo Valdés de León. Miembro del Consejo Asesor Académico de la Facultad de Diseño y Comunicación de la UP. Miembro del Comité de Arbitraje de las publicaciones del Centro de Estudios en Diseño y Comunicación de la Facultad de Diseño y Comunicación de la Universidad de Palermo. Docente de la Facultad de Diseño y Comunicación de la UP. infocedyc@palermo.edu.ar
} 


\section{Variaciones sobre el término}

El término "experiencia" refiere a un fenómeno cotidiano y casi banal, las vivencias que todo sujeto experimenta a lo largo de su vida y también, en algunos casos, a los conocimientos que el sujeto puede incorporar, a partir de su reflexión sobre aquellas experiencias.

Toda experiencia implica, por lo tanto, las impresiones producidas por la realidad -las percepciones así como las producidas por la interioridad- las intuiciones: La experiencia pone en contacto -aunque no siempre de manera placentera- la subjetividad y la sensibilidad; pero también los prejuicios, con la indiferente opacidad de la realidad objetiva. La experiencia, vía privilegiada de acceso al conocimiento empírico, lo es también, paradójicamente para el desconocimiento, puesto que incluye situaciones afectivas, emocionales, ideológicas o religiosas, donde el sujeto de la experiencia se eclipsa, alienándose en otro.

En su versión estrecha, científica, la "experiencia" se traduce en "experimento", como conjunto objetivo, ordenado y reglamentado de operaciones materiales e intelectuales, destinado a producir nuevos conocimientos 0 a verificar y demostrar empíricamente enunciados teóricos. La pretensión de verdad de las hipótesis, al ser confrontada -" realmente" - con una serie pública y protocolizada de experimentos, será verificada o refutada; sin que de la experimentación, por sí misma, surja la institución de una verdad: Desde Karl Popper (1934, 1937), es sabido que el valor epistemológico de la experimentación radica, la más de las veces en refutar hipótesis "falsas" que en validar las verdaderas.

La experimentación científica implica el diseño de una estructura artificial -el "laboratorio" - artefacto 0 artificio en donde se reproducen, en condiciones controlables y mensurables, las condiciones en las cuales el fenómeno a observar se produce "en la realidad" : Este deslizamiento inevitable modifica, de manera inexorable, la "naturalidad" del fenómeno, merma a la cual contribuyen las implicaciones subjetivas del observador, sus supuestos ideológicos y el paradigma científico de la época, que modela y limita su horizonte observacional -sin pretender indagar en sus determinaciones inconscientes.

La experimentación como método aparece en los orígenes de la ciencia M oderna - Roger Bacon, 12201292, y Galileo, 1564-1642, por citar dos nombres emblemáticos -, pero conviene puntualizar, primero, desde un punto de vista topológico, que no toda la ciencia moderna es experimental -atributo que ha sido monopolizado por las Ciencias Naturales con el efecto de excluir del status científico a las Ciencias Sociales por su imposibilidad fáctica y ética de experimentar con sujetos humanos. $Y$, segundo, desde un punto de vista cronológico, que no siempre las ciencias fueron experimentales, es más, en la actualidad, la experimentación científica ha quedado restringida a las grandes corporaciones y a los Departamentos de Defensa de los gobiernos de los países industriales del Grupo de los 7.
Con respecto a la tensión entre experimentación y conocimiento, la Filosofía de la ciencia discrimina dos criterios epistemológicos antagónicos: El empirismo y el racionalismo.

Para el Empirismo -no confundir con la pura empiria, simple práctica sin pensamiento, bastante habitual en la enseñanza- todo el conocimiento procede de la información, más o menos elaborada por la conciencia, que los sentidos nos proporcionan de la realidad exterior, objetiva; en otras palabras: "Todo lo que está en la mente pasó antes por los sentidos", no existe ningún conocimiento a priori. En este sentido, sería conveniente agregar, siguiendo a la Lingüística moderna, que el único a priori observable es la capacidad humana de construir conocimiento a partir de su "disponibilidad al lenguaje", predisposición innata que lo condena al habla.

El Racionalismo, por el contrario, abrevando en las fuentes del pensamiento clásico griego -en ocasiones con evidentes incrustaciones teológicas- sostiene que la experiencia sensible no es válida como vía de acceso al conocimiento si no está precedida por el pensamiento. René Descartes (1596-1650) formaliza la filosofía racionalista (El discurso del método,1637) - desde una concepción dualista que distingue una res cognosens, el "espíritu", y una res extensa, la "materia"; Descartes introduce el concepto de la duda metódica como camino válido para acceder al conocimiento verdadero y la categoría de verdad apodíctica, esto es, aquel enunciado que por su claridad y distinción es reconocido por el espíritu como evidente por sí mismo, lo que hace innecesaria su verificación experimental. Su célebre aforismo Cogito ergo sum, que funda al sujeto en el pensamiento y por el pensamiento no es, en última instancia sino un acto de lenguaje, al tiempo que es un acto de fe en el sentido cristiano del término.

El lector habrá advertido que por detrás de esta discusión de carácter epistemológico se percibe el conflicto entre concepciones antagónicas del mundo, la del Materialismo -o si se prefiere del Realismopor un lado y la del Idealismo filosófico por el otro. Por otra parte, sería erróneo suponer que la experimentación es patrimonio exclusivo de las ciencias: En las Artes, la experimentación es parte constitutiva de su proceso de producción, aunque cumple una función diferente. En efecto, en las ciencias, como ya se dijo, la experimentación tiende a encontrar o verificar una regularidad, en última instancia probabilística, regularidad que se da por supuesta dentro de un orden "natural" preexistente en la realidad material; en cambio, el objetivo general de las Artes -en el sentido más amplio del término, desde una pieza teatral o una sinfonía hasta un "cuadro" o un poema- es producir un objeto que no existe en la realidad material 0 , mejor, cuya existencia no estaba prevista en el "orden" existente en la cual "falta", de donde la experimentación se endereza, no a la verificación o refutación de alguna "verdad" sino a producir algo realmente verdadero". En oposición al método hipotético-deductivo propio de las ciencias, en las Artes se procede por inducción, 
por inferencias o "iluminaciones", de cuya arqueología en el aparato psíquico del sujeto Sigmund Freud dio cuenta con la introducción de la categoría de pulsión o "Trieb" y los mecanismos de sublimación. (Freud, 1930/1998)

En términos más generales, la experimentación en las Artes se hace más evidente en los momentos de ruptura de su historia, por la emergencia y construcción de técnicas, materiales, temáticas, públicos y tratamientos formales nuevos, que se proponen subvertir el paradigma vigente. Esto fue lo que ocurrió durante el Renacimiento italiano -que no fue, como se suele predicar, un simple "reciclaje" de la herencia cultural y artística greco-latina-; la irrupción del Barroco y más adelante del Romanticismo fueron también momentos de ruptura y cambio. Entre finales del siglo XIX y principios del XX se produce la irrupción de las "vanguardias artísticas", cuyas esquirlas, convenientemente mediatizadas y monetizadas, todavía nos alcanzan.

La diferencia, ontológica, entre ciencias y artes, como formas de conocimiento se verifica también en el diferente sentido que el término "experimental" tiene para ellas.

Para la Ciencia - ese supuesto saber sin sujeto - lo "experimental" describe un estado incompleto e imperfecto del proceso u objeto, que aún no ha superado todas las comprobaciones técnicas, económicas y legales indispensables para su inserción en el Mercado, en tanto el producto - como ocurre, para dar ejemplos actuales, con las drogas para prevenir o remitir el SIDA o el cáncer o las investigaciones sobre el "mapa" del genoma humano o los experimentos de clonación de seres humanos cuestión que además genera controversias éticas y teológicas que exceden el campo de la ciencia.

En cambio, en las Artes, lo "experimental" remite a obras que aunque "terminadas", admiten y promueven la participación, la improvisación y la espontaneidad y que por su carácter trasgresor y provocativo, son presentadas, en general a públicos minoritarios de "iniciados" cuya adhesión o complicidad se da por descontada, casi siempre en salas no convencionales -la mítica "cueva" del Once donde nació el rock nacional- por afuera, al menos al principio, de los circuitos comerciales.

Para continuar nuestra indagación sobre la experimentalidad, haremos un breve recorrido sobre los avatares históricos de sus relaciones con las ciencias.

\section{Surgimiento, apogeo y decadencia de la experi- mentación en las ciencias}

La experimentación instaura un espacio de conflicto en el cual la teoría se confronta con la empiria, -el enunciado con lo fáctico, el saber con la verdad-con el auxilio de una tekné que garantiza razonablemente la validez de la experiencia, cuyos resultados, en la medida de lo posible, deberán poder ser cuantificados. Entendida de esta manera, la experimentación se ha convertido, en el imaginario social, en un atributo -condición y signo- de las ciencias, en especial de las Ciencias Naturales, aquello que las diferencia de otras modalidades de producción de conocimiento y las legitima como portadoras del "verdadero" saber. Como ocurre con toda "verdad" consagrada, un rápido análisis nos demostrará que ésta tampoco es verdadera. En primer lugar no todas las ciencias han tenido que recurrir a la experimentación para validar y universalizar sus proposiciones. En efecto, el núcleo más "duro" del pensamiento científico, las Ciencias Formales, se fundamenta en axiomas abstractos que no son demostrables empíricamente, esto es, que no pueden demostrarse ni validarse mediante la experimentación.

A falta de esa imposible verificación fáctica, la verdad de los razonamientos lógico-matemáticos se sostiene mediante reglas deductivas -codificadas por August de Morgan (1847)- reglas que permiten obtener, a partir de premisas reputadas verdaderas nuevos enunciados que conservan el valor de verdad de la premisa. Proposiciones del tipo: "Dado $p$, entonces $q$, si $q$ no se produce, entonces $p$ es falso" ( $p>q, \sim q$, $\sim p$ ) se demuestran por su propia auto evidencia, su carácter formal excluye cualquier encuentro -o encontronazo- con la realidad fáctica.

Es interesante constatar que, en el otro extremo del arco del conocimiento, en el vasto territorio discursivo y especulativo de la filosofía, tampoco resulta necesaria -ni pertinente, ni posible- la práctica experimental: De los enunciados filosóficos sólo se demanda como criterio de "verdad" , una cierta coherencia lógica entre sus postulados.

Mutatis mutandi algo similar ocurre en el territorio, mas problemático, de las religiones, en particular, en el interior de la tradición judeo-cristiana. En el conocido episodio de la aparición de Dios a Moisés, bajo la forma de zarza ardiente y ante la nada ingenua pregunta de éste acerca de qué Nombre debe darle, Dios responde: "Yo soy el que soy" (Eh' yé asher eh' yé, Éxodo 3:14), enunciado indemostrable empíricamente, en la misma línea discursiva del Cogito ergo sum cartesiano, pero de tal potencia simbólica que funda la religión hegemónica en Occidente desde hace casi 2000 años.

Podemos afirmar, entonces, que tanto el conocimiento científico, como la filosofía y la religión occidental, fundamentan su pretensión de "verdad" en meros actos de lenguaje no contrastables con la realidad, en enunciados cuyo valor de verdad es autoevidente, su fundamento último es, pues, una creencia que se sostiene como puro acto de fe, fe que también puede ser de carácter laico.

En segundo lugar, la ciencia occidental, en sus orígenes griegos, no utilizó la experimentación como fuente de conocimiento, salvo que se confunda al placentero baño de inmersión de Arquímedes con una experiencia científica -baño del cual, según la leyenda, brotó una de las leyes fundamentales de la física. En sus orígenes, la Ciencia occidental no se propuso objetivos pragmáticos ni utilitarios, asumiéndose como una de las ramas de la filosofía -Aristóteles-; todavía en la primera Modernidad, los protocientíficos de entonces se auto designaban " filósofos naturales". Resulta oportuno recordar que, en este 
aspecto, el pensamiento clásico se propone establecer el orden, imaginario, de un Cosmos armónico, estático y autosuficiente -las "Ideas" platónicas, el Dios del Estagirita, concebido como "motor inmóvil" -orden que rechaza el cambio, el movimiento, como expresiones del Caos y de la imperfección: El pensamiento clásico, siguiendo a Nietzsche, está más cerca de Apolo que de Dioniso, y es de orden binario, nunca dialéctico. En este contexto, Heráclito de Efeso, el Oscuro, viene a ser un outsider.

La Iglesia, tras la descomposición del Imperio Romano, se apropia de la tradición filosófica clásica, adaptándola a sus principios doctrinarios gracias a sus intelectuales orgánicos, los llamados "Padres de la Iglesia"; San Agustín, San Gregorio Magno, San Jerónimo y San Ambrosio, entre otros. La Ciencia, por lo tanto, monopolio eclesiástico, mantendrá vivo aquél espíritu de orden y armonía, de repetición cíclica de lo mismo, como saber repetitivo y dogmático de un Universo jerárquicamente estructurado cuyo centro es la Tierra -y Roma el centro de ese centro- a imagen y semejanza de la estructura rígida, estamental y orgánica de la sociedad medieval; saber ajeno, cuando no hostil a la producción material, al trabajo físico considerado "propio" de las clases bajas -siervos, campesinos y artesanos-, saber que desprecia las "artes mecánicas" y que rechaza, cuando no condena, la experimentación y aún la simple observación, en tanto estas puedan cuestionar el dogma. La enseñanza, también monopolio eclesiástico, asumirá las mismas características: Lectura en voz alta y comentarios del "domine" sobre los textos sagrados y algunos clásicos expurgados de su paganismo imponiendo un saber canonizado de un mundo inmutable: Nihil novum sub sole.

La experimentación, mientras tanto, quedará relegada a la búsqueda utópica de los alquimistas, siempre sospechados de herejía por sus códigos esotéricos, más cerca de la magia que de la "verdadera" ciencia, la de Tolomeo y Aristóteles.

Ahora sabemos que este divorcio entre la ciencia y la técnica, entre el "saber" y la "práctica", fue una de las causas del atraso tecnológico, en especial en orden a la producción de alimentos que, entre otros factores, determinó el agotamiento y colapso del modo de producción feudal.

\section{Irrumpe la revolución científica}

Tímidamente al principio y con irresistible potencia y arrogancia después, la experimentación surge con el primer Renacimiento, de la mano del incipiente capitalismo mercantil, en algunas ciudades -en rigor, "ciudades-estado" - de Flandes y del norte de la península itálica: En el seno de la vieja ciencia contemplativa, se había ido engendrando un nuevo paradigma, la ciencia moderna, pragmática y utilitaria. La nueva clase emergente, la burguesía, instaura, con arrestos revolucionarios, las figuras del empresario y el ingeniero como los nuevos adalides de una cultura basada en el trabajo. Más adelante se sumará la del científico. Señalemos que el término que designa a la nueva profesión -scientist- aparece tardíamente, en 1840, propuesto por Wheller, no casualmente en el Reino Unido y el apogeo de la revolución industrial. (Capanna, 2004)

La pujante burguesía demanda de las Ciencias "respuestas" prácticas en orden a nuevas tecnologías de producción y gerenciamiento, en el marco de una nueva concepción del mundo que privilegia la racionalidad, la eficiencia y el pragmatismo.

\section{Digresión inevitable}

En este punto se hace necesario hacer notar que gran parte de los instrumentos y materiales utilizados con fines prácticos a partir del Renacimiento fueron en realidad productos de los pueblos "bárbaros" del Medio y Extremo Oriente que el "genio europeo" supo expropiar y utilizar con habilidad en su propio provecho. Hagamos un breve repaso. La brújula y otros instrumentos de medición que hicieron más seguros los viajes de ultramar, posibilitando la saga descubridora. El papel, que vino a sustituir al sumamente oneroso pergamino, facilitando el desarrollo de la imprenta y el impreso -herramienta sin la cual la "revolución cultural" de la Modernidad no hubiera sido posible. (Valdés de León, 2003) La pólvora, gracias a la cual los conquistadores europeos pudieron imponer su superioridad militar sobre los pueblos aborígenes de África, Asia y América.

Ya con anterioridad los griegos habían expropiado y hecho suya otra herramienta fundamental para la producción y comunicación de la cultura, la escritura alfabética "tomada" del alifato fenicio de raigambre semítico y "adaptado" a la lengua de Homero. En esta línea de análisis no resulta ocioso recordar que las letras minúsculas de nuestro alfabeto -denominado "romano" - fueron establecidas en el ochocientos por Carlomagno, soberano de origen "bárbaro" -de la etnia de los francos- convenientemente romanizado y cristianizado.

Pero hay más. El desarrollo del cálculo matemático, sin el cual, como se verá de inmediato, el capitalismo mercantil no hubiera existido, fue posible gracias a la expropiación de los números "arábigos" - y, su verdaderamente revolucionaria inclusión del "cero" como magnitud representable - no obstante lo cual la Europa cristiana desencadenó contra dicha cultura, con supuestos pretextos religiosos, la ofensiva genocida que ha pasado a la historia como las Cruzadas. Sin mencionar la "limpieza étnica" que consumaron los Reyes Católicos, Fernando de Aragón e Isabel de Castilla, en el curso de la intencionadamente denominada "Reconquista" de la península Ibérica.

$\mathrm{Si}$ a todo esto agregamos que uno de los pilares básicos de la cultura occidental -el monoteísmo, con las implicaciones éticas que dicha creencia conllevafue "importado" de Oriente Medio a partir de los textos religiosos del pueblo hebreo -la Torá, que incluye el Pentateudo, el Nevi'm y el Ketuvim, que, con algunas modificaciones, será luego conocido como El Antiguo Testamento- operación que tamién se aplicará al Cristianismo, otro emergente cultural de origen no-europeo -es muy poco lo que queda como producción original del "genio europeo" cuya 
mayor habilidad consistió en asimilar y sintetizar la "creatividad" de las civilizaciones estigmatizadas como bárbaras o "infieles".

En este contexto resulta evidente que el Renacimiento, concebido como el mero renacer de las fuentes europeas de la cultura y el arte occidental exige ser revisado y reescrito.

\section{El cálculo racional}

Sea como fuere, en esta nueva Zeitgeist, el cálculo deviene factor estratégico: La acumulación de capital exige una precisa cuantificación, un control exacto de los costos y beneficios - el sistema de contabilidad por partida doble del humanista Luca Paccioli, autor además de De divina proportione - registro confiable de los movimientos dinerarios, sistemas sencillos y universales de medición - de longitud, de superficie, de volumen, de peso y capacidad - que cristalizarán en el Sistema métrico decimal, producto de la Revolución francesa. En síntesis, la naciente burguesía desarrollará métodos de cálculo estrictos en un mundo de trance de globalización, tras el "descubrimiento" de América, en el cual las mercancías son transportadas a lugares lejanos y los primitivos sistemas de pago pre-capitalistas - trueque de mercaderías, monedas de metal precioso con valor intrínseco - están siendo sustituidos por medios de pago simbólicos: letras de cambio, pagarés, papel moneda, operaciones de crédito y débito, aseguramiento de riesgo - ver El mercader de Venecia, W. Shakespeare - que, en última instancia son sólo y nada menos que asientos contables en los libros de las incipientes instituciones bancarias.

El éxito de un negocio y la adquisición de una fortuna ya no dependen de la imprevisible "fortuna" sino de la ponderación racional de riesgos y ventajas a la luz de información objetiva: El cálculo vence al azar. Surgida en el interior de este paradigma, la Ciencia Moderna arrastra una incoercible pulsión cuantificadora: Aquellas disciplinas cuyos enunciados teóricos no puedan ser matemizados y cuyos experimentos no puedan ser mensurados en términos numéricos quedarán excluidos del Olimpo científico - salvo que se les adose el sambenito de ciencias "blandas". Véase al respecto los argumentos con los cuales el epistemólogo Mario Bunge (1989) denosta al Psicoanálisis. Consecuencia de aquella pulsión, ya desde el Positivismo, la Ciencia impone como criterio de verdad la falacia de las estadísticas. Esta innegable determinación social sobre las ciencias, alcanza para deslegitimar la creencia, aún vigente, en la existencia de una ciencia "pura", neutral y objetiva, afanada exclusivamente en la desinteresada búsqueda de la "verdad" y del bienestar de la "Humanidad".

No resulta extraño entonces que la experimentación florezca en el siglo XIX y principios del S. XX, el "siglo de los inventos", puesto que es el momento histórico en el cual la Revolución Industrial alcanza su madurez, al menos en los países con mayor desarrollo relativo. En este contexto, el científico investiga y experimenta con el objetivo utilitario de generar nuevas tecno- logías que optimicen la producción industrial de mercancías - artefactos o servicios - destinados al Mercado: El "invento" deviene en patente comercial y marca registrada, expediente mediante el cual Alexander Graham Bell se apropió de la invención del teléfono.

Figura paradigmática en este escenario fue, sin duda, Thomas Alva Edison (1847-1931), ex-vendedor de diarios y científico autodidacta que amasará una considerable fortuna, en el mejor estilo del "self made man", tras inventar y comercializar, entre otras innovaciones, el fonógrafo, el megáfono, el kinetoscopio, la primera central eléctrica (Nueva York 1882) además de la silla eléctrica y su propia imagen: El "mago de Menlo Park."

La nómina de científicos e investigadores del período considerado, además de los ya citados es muy extensa, en el vasto mundo de la ciencia y la técnica. Citaremos algunos en orden a su aparición en escena. James Watt, Jean-Baptiste Lamarck, Joseph-Nicéphore Niepce, George Stephenson, Louis J.M. Daguerre, Samuel F.B. M orse, Charles A. Darw in y Louis Pasteur, Edgard J. Muybrgidge, Sigmund Freud, George M élies, Pierre y M arie Curie, August y Louis Lúmiére, Guglielmo Marconi, Wilbur y Orville Wright, Albert Einstein y Max K.E.L Planck. Nunca tan pocos inventaron tanto en tan poco tiempo. Algunos, impulsados por el deseo altruista de contribuir al bienestar de la humanidad -en el espíritu de progreso indefinido que define a la época- otros, en cambio, por el mero afán de lucro o de notoriedad, estos hombres y mujeres -que van desde el inventor de la máquina de vapor, "motor" físico de la Revolución Industrial hasta quienes indagaron en la estructura íntima del ser humano, de la materia y del Universo- modelaron, merced a la investigación y a la experimentación, el mundo en el que hoy vivimos y el sujeto moderno. Ya en el S. XX y con la madurez del capitalismo industrial la figura del científico independiente va siendo sustituida por la del científico asalariado, al servicio de las compañías y de los Estados, instituciones que pasarán a ser agentes activos de la investigación.

La II Guerra M undial marca, en este sentido, un punto de inflexión. El anterior conflicto -la "Gran Guerra", 1914-1918- había dejado una enseñanza: las guerras no se ganan en los frentes de combate - o no sólo en ellos -, allí a lo sumo se ganan o pierden "batallas". Las guerras se ganan o se pierden en la retaguardia: El desarrollo industrial y tecnológico que permite la producción creciente de armamentos y su flujo sostenido hacia el frente. En consecuencia, las potencias beligerantes van a destinar cuantiosos recursos económicos y humanos en investigaciones destinadas a la invención y fabricación de armas y tecnologías bélicas con mayor poder mortífero, capaces de decidir el rumbo de la contienda: el sueño del "arma definitiva" obsesionaba tanto a F. D. Roosvelt como a A. Hitler. En los Estados Unidos, y a instancias de Einstein, se desarrolla el Proyecto M anhattan (1942) que convoca a los más prestigiosos físicos de la época -Robert J. Oppenheimer, Entico Fermi, entre otros- cuyos trabajos serán verificados "experimentalmente" en 
Hiroshima y Nagasaki - 6 y 8 de agosto de 1945, primeros bombardeos a poblaciones civiles con armas nucleares- que ocasionaron ciento treinta y siete mil y cuarenta mil muertos respectivamente- y pusieron fin a la guerra. Con anterioridad, los científicos del III Reich, comandados por el físico Wernher von Braun, habían venido desarrollando en la base de Peenemünde bombas autopropulsadas de mediano alcance -las V-1 y V-2-, origen de la misilística actual. Tras la derrota nazi, von Braun continuó su "carrera" en los Estados Unidos, donde llegó a ocupar cargos importantes en la NASA y en la industria privada. (Acerca de los problemas éticos que el hecho de trabajar para la destrucción suscitó en algunos científicos de la época, véase Copenhague de Michael Frayn, basada en el encuentro que en dicha ciudad tuvieron Niels Bohr y Werner Heinsenberg en 1941) Concluido el conflicto, la rivalidad política entre las potencias triunfadoras, se trasladó al terreno de la ciencia y la tecnología: El fin del monopolio atómico, la "carrera" espacial y es sabido que, en definitiva, la caída del "socialismo real" en 1991 fue también consecuencia del atraso soviético -sobre todo en las tecnologías más sofisticadas, en particular, en el campo de la informática.

En la actualidad, las grandes inversiones en capital, equipamiento y personal especializado que la investigación científica requiere ha tenido como efecto no deseado que únicamente las grandes empresas transnacionales y los Estados de los países más desarrollados -en especial, sus Departamentos de Defensa- estén en condiciones de proyectar y concretar programas de investigación y experimentación. La asignación de recursos (Oscar Varsavsky, 1975) por parte del estado y de las corporaciones ha pasado a ser el factor determinante de la investigación: Quien financia impone qué problemas se deben investigar, es más, determina qué cuestiones deben ser consideradas como "problemas" -que no serán sino aquellas que se relacionen con los intereses económicos de las corporaciones y los intereses estratégicos de los Estados Mayores de las grandes potencias.

La Ciencia ha devenido industria y el conocimiento, mercancía: La producción de conocimientos se ha burocratizado. Más que a investigaciones originales, el científico se dedica a redactar "papers" cuya publicación en las revistas especializadas favorece su ranking profesional y su status económico. (Un estudio más detallado de esta cuestión en Oscar Varsavsky, 1975) Por otra parte, la brecha de conocimientos existente entre los países desarrollados y los de la periferia se ha tornado infranqueable- y continúa ampliándose en manera exponencial: El porcentaje del P.B.I. que los países del grupo de los 7 destinan a investigaciones de base y al desarrollo de nuevas tecnologías, que no son redituables en el corto plazo, es incomparablemente superior al que pueden destinar a tales fines los países periféricos, en muchos de los cuales, además, al compás del pensamiento neoliberal, la inversión en Ciencia y Tecnología es considerada casi como un gasto inútil. (Recordar los exabruptos que el ex Ministro Domingo Cavallo dirigió en su mo- mento a los investigadores)

El atraso tecnológico, al tiempo que nos coloca en situación "tecno-dependiente" -exportamos soja para canjearla por chips- ha reducido la experimentación a su mínima expresión y al científico investigador en una especie en extinción, que apenas sobrevive heroicamente gracias a la "prepotencia de trabajo", como diría Roberto Artl, de algunos profesionales e instituciones.

\section{Artes y experimentalidad}

A medida que las ciencias van abandonando la práctica experimental - al menos en el sentido que el imaginario social le atribuye a este término - ésta se desplaza al más fértil territorio de las Artes, en el cual cumple, como ya hemos indicado, funciones radicalmente diferentes.

La tensión experimental en las artes contemporáneas puede rastrearse, entre otros, en Jonathan Swift (Una modesta proposición), Lewis Carrol (las dos Alicias), Stephan Mallarmé (Un golpe de dados no puede vencer al azar ) y Alfred Jarry, entre otros. De este último destacamos “ Ubú Rey” (1896) concebida para ser representada por marionetas, que reintroduce en la escena y en la literatura decimonónica la comicidad popular, ácida e irreverente de Rabelais; Jarry fue el fundador de la "parafísica" o ciencia de las excepciones, y su legado será continuado por el Surrealismo. Resulta irónico que aquella obra, escrita por Jarry como una broma estudiantil, y como tal transgresora (la primera palabra que el Padre Ubú pronuncia en escena es "merdre", deliberada deformación del término) venga a terminar transformada en una "ópera", y como tal, "culta" a pesar del agregado de "bufa", traducida al alemán y con música compuesta por un autor polaco, Krzystof Penderecky (1991) ex-vanguardista devenido conservador; obra que fuera estrenada en el Teatro Colón en la actual temporada.- prueba incontrastable de cómo todas las vanguardias, aún las más provocadoras, terminan siendo fagocitadas por la cultura dominante. (Hobsbawn, 1998)

La experimentalidad presente en el Manifeste $d u$ Futurisme (Le Figaro, París, 1909) de Filippo Tommasso Marinetti, con su grandilocuente ruptura con el academicismo y la apología de la civilización industrial, las máquinas, la violencia y la guerra -que concluirá con la adhesión del movimiento al fascismo italiano-, se manifiesta con toda su potencia en la revulsiva estética dadá: Marcel Duchamp (La casada desnudada por sus solteros), Erik Satie (Tres fragmentos en forma de pera, Música para amueblamieto, en línea con el Futurismo ruso: Una bofetada al gusto público, 1912, de V. Chlebnikov, V. M aiakovskj y D. Burlyuk). De manera más amable, la experimentalidad está presente en los cabarets y el teatro musical durante la fugaz república de Weimar (Die Dreigroschenoper, 1928, conocida como La ópera de tres centavos, de B. Brecht y K. Weill) y en la experiencia plástica, musical y coreográfica del Ballet Triádico (Stuttgart, 1922) de Oskar Schlemmer, producida al calor de las tendencias no funcionalistas de la Bauhaus de 
Weimar -si bien Schlemmer le había bocetado en 1914, en la época del controvertido estreno de La consagración de la primavera de Igor Stravinsky por los Ballets Rusos de Serge Diaghílev, en París.

En la música las tendencias experimentales -presentes ya en Richard Wagner (Tristán e Isolda, ópera en la cual el discurso musical se empieza a alejar de los cánones tonales clásicos) y en Gustav Mahler, serán formalizadas con la designación del "atonalismo" por Arnold Schomberg, y desarrolladas por la Escuela de Viena (1908-1914) que incluye además a Anton Webern y Alban Berg. De este último, autor de las óperas Wozzek y Lulú, con marcada impronta expresionista - y para ilustrara las múltiples convergencias que dan forma al arte de posguerra en la Europa central - destacamos su Concierto para violín (1935) subtitulado A la memoria de un ángel. El "ángel” en cuestión no era otro que la hija de Alma Mahler años atrás esposa de Gropius en el período Weimar de la Bauhaus: Después de su única visita a la escuela, Alma decidió no volver más, asqueada por el olor a ajos que impregnaba el edificio, consecuencia de la rigurosa dieta macrobiótica que el delirante Johannes Itten hacía ingerir a sus alumnos del "curso preliminar", Vorkurs, como parte de su método pedagógico (Whitford, F., 1984/1991) (El 26 de agosto del presente año el concierto de Berg, Dem Andenken eines Engels, fue interpretado en el Teatro Colón por la Filarmónica de Buenos Aires actuando como solista el virtuoso letón Gideon Kremer, con buena repercusión en el público y la crítica especializada).

En la misma línea de experimentación de la Escuela de Viena están empeñados Béla Bartok, Paul Hindemith, Artur Honneger y Darius Milhaud. Por esta vía Schönberg y Webern arriban al dodecafonismo (Pierre Boulez, Karlneiz Stockhausen) y a la música serial. En Estados Unidos, un epígono de Schönberg, John Cage, introduce el factor aleatorio en la composición musical, privilegiando el rol del intérprete, y con Roartorio, estrenado en 1980 por Pierre Boulez, hace colisionar la experimentación musical con la literaria al tomar como tema de esta obra, fragmentos del Finnegan's Wake de James Joyce. La misma experiencia había sido acometida por el italiano Luciano Berio en 1958, quien a instancias del lingüista E. Samguinetti -tras del cual se percibe la robusta sombra de Ferdinand de Saussurecompone su Tema. Homenaje a Joyce, basándose en el capítulo "Las sirenas" del Ulises. Como se ve 0 , mejor debería escribirse, "como se oye", la experimentación tiende a disolver las fronteras entre los "géneros", la escritura, la oralidad, el ritmo y la musicalidad, "fusión" que ya había sido intentada por Lew is Carrol en Alicia en el país de las maravillas. En el riquísimo campo de la música experimental -en el cual habría que incluir la música concreta, la electroacústica y la electrónica- no queremos dejar de mencionar la corriente Minimalista, cuyo origen podemos establecer en las artes visuales (Kazimir Malevich, Cuadro negro sobre fondo blanco, 1915), que como "Minimal Art" resurge en Nueva York a finales de la década del 50' en la plástica y en la música. Ésta se estructura sobre la repetición, sin desarrollos armónicos ni variaciones, de un sujeto temático, ya preanunciada por Mauirice Ravel en su popularísimo Bolero, corriente en el cual se destacan John Adams y Philip Glass. De este último de interpretó en el Colón, la música especialmente escrita para la versión, histórica, del Drácula, en la interpretación de Bela Lugosi de la década del ' 30.

En las artes plásticas, al menos desde 1917 (Marcel Duchamp, Fuente), la "exposición" tradicional de cuadros ha venido perdiendo sentido, desalojada por la presentación de objetos de la más variada índole, o por el diseño y construcción de "instalaciones" efímeras que obligan al público a desplazarse por recorridos predeterminados, con el agregado, en la actualidad, de efectos luminotécnicos, y en algunos casos, con efectos sonoros, música o ruidos especialmente compaginados dentro de un contexto espacial de carácter escenográfico.

La ruptura con lo pictórico tradicional vino aparejada con el desarrollo de la fotografía y el perfeccionamiento de las técnicas de reproducción gráfica y la democratización de la difusión y circulación de las "obras de arte", que han quedado privadas, según observara agudamente Walter Benjamín, del halo "sagrado" que las consagraba como objetos únicos, piezas originales, al alcance exclusivo y privado de la élite. Por afuera de los recintos cerrados, otras tendencias como el "Land Art" realizan intervenciones traumáticas sobre entornos "naturales", lo que exige costosos equipos de producción (Christo Javacheff y Jean Claud), muy lejos de las primeras e ingenuas "intervenciones" que se limitaban a arrojar baldes de pintura a las espesas aguas de los canales venecianos. Como es lógico, en estas "obras", la "mano creadora" del artista ha desaparecido, así como el contacto físico con la materia, en tanto el proyecto es realizado, en un ejemplo clásico de división del trabajo, por un equipo de técnicos y especialistas contratados al efecto, que el "artista" supervisa: Sol Lewitt y su proyecto para la Fundación Proa, teledirigido desde Nueva York (2002). Enumerar las experimentaciones que jalonan el desarrollo de las artes plásticas en la segunda mitad del siglo XX -desde el Pop-Art y The Factory hasta el Arte conceptual o L'arte povera, excede las intenciones de este trabajo (Una guía práctica de este período se puede encontrar en Lucie-Smith, E. 1996/2000).

Como resultado de este proceso de fusión y síntesis, en la actualidad la experimentación en las artes -en algunos casos, devenido en mero "experimentalismo" - se concentra con mayor énfasis en las artes del espectáculo, tras la brecha inaugurada por Bertolt Brecht con su concepción de un teatro épico, no aristotélico, que con el recurso de la distanciación no busca la catarsis del público, sino por el contrario, una mirada objetiva crítica, con obras nunca " terminadas", experimentales, siempre sujetas a los cambios que surjan de los sucesivos ensayos y representaciones. Desde otro horizonte estético y político, las innovaciones de Eugéne lonesco, Samuel Beckett y Antonin Artaud, entre otros (Teatro del Absurdo, Teatro de la 
Crueldad en su denominación mediática) han puesto en cuestión las convenciones del teatro burgués: La unidad de espacio y tiempo, la progresión dramática, el texto "de autor", la separación física entre la escena y los espectadores, el tiempo "real" de cada acto, se disuelven en la producción grupal de la dramaturgia, la inclusión -con reminiscencias circenses- de la acrobacia, el protagonismo que adquieren los " objetos" -con o sin animación- y el dispositivo escenográfico, la disposición de nuevos espacios donde los actores y el público están en contacto físico -al estilo del teatro popular tardo medieval- configurando un nuevo tipo de espectáculo, producto de una constante experimentación, muy alejado del modelo clásico (De la guarda, El periférico de objetos, y, en especial, La Fura dels Baus)

Con la incorporación masiva e indiscriminada de la informática en las artes visuales, cuyos límites -como las fronteras de los Estado-Nación, se van tornando cada vez más borrosos- entran a pendular entre un todavía no definido "arte digital" y las "artes performáticas", género ambiguo en el cual diversas expresiones artísticas -plástica, música, actuación, danza, literatura, "diseño", escenografía- confluyen, no siempre de manera armoniosa, en una estética del gesto -que hunde sus raíces en el "happening" de los '60 -configurando eventos "multimedia" producidos con generoso despliegue tecnológico pero con discutibles resultados artísticos (Buenos Aires Tour de Jorge Macchi, presentado en la última edición de Arte BA.)

La inclusión de la experimentalidad en algunos géneros marcadamente tradicionales -monopolizados por la élite- la ópera, en particular, no ha sido bien recibida ni por el público ni por la crítica. Valgan como ejemplos recientes, la gigantesca e inhóspita sala de hospital en el cual transcurría el tercer acto de La traviata (G. Verdi, representada en el Luna Park, 2002), el dispositivo escénico (cintas trasportadoras) diseñado por Kuitka para El Holandés Errante (R. Wagner) en el Teatro Colón (2003), abucheado por los abonados; la fría recepción que tuvo el estreno de Fuego en Casabindo (Virtú Maragno sobre la novela homónima de Héctor Tizón) ópera nacional cuyas innovaciones formales y temáticas obtuvieron como respuesta la fuga de parte del público durante el entreacto.

Nuestro examen de las relaciones -como se ve, no siempre felices- entre las artes y la experimentalidad estaría incompleto si no mencionáramos las consecuencias negativas que la incorporación de las nuevas y prepotentes "tecnologías" han ocasionado en las artes y en la cultura contemporáneas.

En el cine, sobre todo en el norteamericano, se observa que los "efectos especiales" - concebidos al principio como auxiliares del relato fílmico- han pasado a ser los protagonistas de muchos filmes, sustituyendo al desarrollo dramático. Este recurso válido y hasta inevitable para aquellas películas que derivan del comic, como X-men o El hombre araña, deviene impropio en aquellas cuyo origen es de carácter literario (Troya, donde hasta los mismos dioses olímpicos han sido suprimidos para dar lugar a los "efectos", merced a un millonario presupuesto)

En otro orden, la cultura visual predominante, basada en la fragmentación y la velocidad, características estéticas y funcionales del video clip y la habitualidad del zapping, promueve en las generaciones jóvenes una concepción fragmentaria de la realidad, a tono con la visión -típica del Posmodernismo- de la historia y la cultura como collage o patch work: Amontonamiento azaroso de discursos parciales, sin relaciones estructurales ni núcleos generadores de sentido, como no sea un "presente" interminable -además de la fetichización de las categorías de "joven" y "moderno" cono instancias eternas y metafísicas, privadas de historicidad.

No resultará exagerado sostener que como correlato a este contexto mediático -estimulado además por el uso compulsivo de Internet- el discurso juvenil aparece fragmentado, su repertorio lingüístico sumamente restringido y con evidentes dificultades para acceder con fluidez al pensamiento abstracto y a su verbalización.

De cualquier modo, queda en claro, a manera de síntesis, que las artes del S. XX están funcionalmente asociadas a la práctica de la experimentalidad - más allá de los resultados estéticos que hayan producido así como de la perdurabilidad en el tiempo de sus propuestas programáticas. Su pulsión por impugnar el ordenamiento existente, su pasión por ampliar el horizonte de lo posible son, sin duda, meritorios. Tratemos de ver entonces como operan estas tensiones en las disciplinas proyectuales.

\section{El método experimental y el diseño}

La Revolución Industrial, en especial promediando el siglo XIX, trae aparejada una tajante división entre el trabajo físico, manual y el trabajo intelectual, técnico y organizativo. Por esa brecha, junto al surgimiento de una nueva clase social -el proletariadoemerge una nueva profesión, la del proyectista o diseñador, representada en primer lugar por los ingenieros y los arquitectos, a los cuales se irán incorporando más tarde técnicos en el área industrial, y más recientemente, en la comunicación visual. Las profesiones citadas en primer término, al adquirir status universitario logran un mayor reconocimiento social, en tanto el resto de los diseños quedan relegados como disciplinas menores, cuando no, a meros "oficios".

No obstante estadiscriminación, el método proyectual es común a todas estas actividades, puesto que el "Diseño", contrariamente al sentido común que lo asocia con "objetos" o "dibujos", se define como un proceso de programación racional que, a partir de un acto de lenguaje, conduce a la producción industrial de bienes y servicios (Más adelante desarrollaremos este concepto)

El proceso proyectual se inicia con la demanda de un comitente, empresa o institución, que formula un encargo concreto al profesional. Este realiza, en primer término, un relevamiento de los datos técnicos necesarios para plantear el problema de diseño en 
términos razonables de funcionalidad, costos y factibilidad, ensayando distintas alternativas prácticas de solución. Eligiendo, mediante procesos de verificación específicos -más o menos sofisticados- el "partido" que mejor responde a los requerimientos económicos y funcionales del comitente, dentro de plazos previamente convenidos, recibiendo como retribución honorarios estipulados legalmente. Su trabajo se concreta con la entrega de documentación técnica -memorias, planos, prototipos, maquetas, originales, etc. según la especialidad- y, en general, toma a su cargo la dirección de la "obra" o la supervisión del proceso de fabricación industrial del producto, -lo que exige una determinada idoneidad técnica- cuyo destino, como bien de uso o de consumo, o como servicio, es el M ercado. Como se ve, el proceso proyectual no es una acción espontánea 0 autónoma del diseñador, se pone en marcha en tanto y en cuando exista una demanda concreta, de orden verbal, ante la cual el Diseño se constituye como "respuesta" eficiente.

Todo el proceso proyectual, en definitiva, una secuencia ordenada de toma de decisiones, está regido tanto en las etapas "creativas" -la búsqueda de soluciones- como en las etapas "técnicas" -la implementación material de aquellas soluciones- por la más estricta racionalidad, por la deliberada exclusión de toda tentación lúdica, propensión aleatoria o veleidades estetizantes, en el espíritu del Funcionalismo propio del "Movimiento Moderno" para el cual, como es sabido, la forma "sigue" dócilmente a la función, según la fórmula form fol lows function, acuñada por L.M. Sullivan; en el marco de un proceso marcadamente consciente, donde toda decisión debe estar sostenida por alguna "razón", la obra de personajes como Antonio Gaudí, por citar un caso notorio, resulta al menos incómoda, por inadecuada al dogma Modernista.

El método proyectual garantiza, dentro de ciertos límites, a quien lo practica, que si observa rigurosamente los pasos ordenados por el canon, el resultado será la respuesta más adecuada "en función" de las diversas variables que condicionan el proceso -que van desde el presupuesto disponible, hasta el contexto político y los límites estéticos imperantes. Para matizar, en alguna medida, el carácter toscamente lineal del proceso descripto, se suele adicionar el término "iterativo", tomado en préstamo de las Matemáticas como aproximaciones sucesivas o serie de operaciones o pasos de programas que se repiten hasta que quede satisfecha una condición previamente determinada.

Sea como fuere, queda claro que el "método" no puede dar cuenta de los procesos subjetivos capaces de producir soluciones innovadoras, no "programadas" ni programables.

Para intentar salvar esta falencia, algunos autores (Joan Costa, 1988) incluyen, como parte del "método", una etapa de "incubación" en la cual, al parecer, las "ideas" son procesadas 0 , mejor, se procesan a sí mismas, como entes dotados de vida propia que se autodeterminan por "afuera" o al margen del sujeto, dando como resultado una "iluminación" o "idea", cuya aparición no puede ser explicada en términos de racionalidad.

Esta peculiar terminología entre biologista y mística -del acendrado misticismo de Costa ya nos hemos ocupado en un trabajo anterior- ilustra las dificultades que encuentran los defensores del "método" para explicar la intrusión de elementos alógenos, no previstos -es más, rechazados- por el "método", vinculados a la sensibilidad y la emotividad y de innegable prosapia inconsciente, irreductible a la razón, imposible de cuantificar.

El dogma funcionalista -cuya formalización suele atribuirse erróneamente a Bauhaus- encierra una contradicción insoslayable al yuxtaponer en relación de subordinación los términos función y forma mutuamente excluyentes, toda vez que la función, en tanto eficacia instrumental con arreglo a fines es matemáticamente cuantificable, mientras que la forma en tanto cualidad que el sujeto atribuye al objeto según su percepción y sensibilidad, es inconmensurable.

Conscientes de esta dificultad, de orden ontológico, en la Escuela Superior de Diseño de UIm -anacrónica "heredera" de los restos bauhausianos- se intentó solucionarla transfiriendo los términos cuantitativos de la Teoría Matemática de la Información (C. Shannon, W. Weaver, 1949) al análisis estético y a la práctica del Diseño, elaborando fórmulas matemáticas que permitirían "medir" la belleza de la forma (Rolf Garnich: Método matemático universal para la descripción objetiva de las condiciones estéticas en el proceso analítico y para la proyección formal generadora en el proceso sintético de los objetos del diseño, 1968, citado por Bernhard Burdel ([1991],1999). Lo largo y farragoso de este pintoresco título habla a las claras de los disparates a que suele conducir el uso abusivo de la "razón".

Fuera del ámbito académico, concretamente, desde los medios de comunicación "para las masas", buscando resolver el "misterio" de la irrupción de factores no previstos en el proceso proyectual, se ha acuñado el término "creatividad" -rápidamente apropiado por la Publicidad que lo ha convertido en el nombre propio de una "profesión" - término carente de todo contenido científico no obstante lo cual ha conseguido carta de ciudadanía en las instituciones académicas - no precisamente en la Facultad de Psicología - sin que nadie, por ahora, haya podido precisar con exactitud, requisito epistemológico elemental, en que consiste esta "cacareada" creatividad, cuestión sobre la que volveremos más adelante. Por este canal, la "creatividad" termina convirtiéndose en show, esto es, se faranduliza.

Hasta aquí podemos concluir en que, por su propia estructura lógica y por la función económica que cumple en la vida de la sociedad, el "método proyectual", en tanto tal, obtura, torna impracticable por antieconómico, todo intento de carácter experimental en las disciplinas del Diseño- experimentación que resultaría onerosa en la relación costo-beneficio del proyecto y riesgosa en orden al paradigma 
ideológico dominante.

Esto es así por cuanto la acción de experimentar tiene siempre, un talante contestatario, puesto que experimentar implica poner en cuestión, interpelar un orden establecido, físico o social: ¿Esto es necesariamente así? ¿No podría ser de otra manera? y, en todo caso, ¿Por qué es como creemos que es?

En tal sentido, experimentar es poner en cuestión una "verdad" consagrada, sacralizada por la sociedad como tal, y como tal, indiscutible - trátase del geocentrismo, la generación espontánea, el flogisto o la propiedad privada de los medios de producción.

\section{El método proyectual y la enseñanza del Diseño} Conforme la enseñanza del Diseño se institucionaliza, los métodos de "transmisión" de su práctica, reproducen, replicando, el esquema cartesiano del " método proyectual" en el cual, como se ha señalado, no hay espacio -ni lógico, ni temporal, ni institucionalpara la experimentación.

Los métodos de enseñanza, por lo tanto, privilegian el resultado fáctico, el "producto", en detrimento de la reflexión acerca del proceso. La crítica, que es la enseñanza que el docente imparte desde su sitial de sujeto supuesto saber, se centra -en las rituales "colgadas" colectivas- en el análisis formal y técnico, con exigua o nula consideración de los presupuestos ideológicos, las instancias de toma de decisiones y los procesos subjetivos, afectivos y emocionales que subyacen al proyecto, y en definitiva, lo conforman. Por otra parte, suele velarse -por lo general- toda referencia a las exigencias reales del Mercado y de la sociedad, omisión interesada mediante la cual el Diseño termina constituyéndose como en ente ideal, ajeno o "por encima", del contexto social del cual es producto. Consecuencia de este fermento son los proyectos que hemos llamado "diseño-ficción", sin relación alguna con la realidad. Casos paradigmáticos: "proyecto" de señalización del monasterio descrito por Umberto Eco en El nombre de la rosa, "proyectos" de diseño de billetes de banco para países de fantasía, "proyectos" de diseño de identidad visual para empresas inexistentes, que el alumno "inventa" y denomina a su antojo, y otros no menos desopilantes en los cuales, en el mejor de los casos, experimentar se confunde con denegación de lo real, que es la materia propia del experimento.

Otro síntoma de la estrechez conceptual del método, en su faz didáctica, lo percibimos en la desconsideración casi total por las cuestiones teóricas y prácticas relacionadas con la Retórica y la siempre problemática transferencia de sus operaciones y figuras al "lenguaje" visual, así como el desconocimiento de los deslizamientos de sentido, metonímicos y metafóricos, vía regia de acceso al proceso primario, los mecanismos de desplazamiento y condensación descriptos por Freud (1900), que están en la fuente misma del pensamiento creativo - en última instancia, "subversivo" en tanto elude con astucia mediante el ardid retórico el control superyoico de la "razón".

El desencadenamiento productivista de la libre asociación -dentro de los márgenes que impone la pertinencia semántica respecto del objeto-en-diseñosegún la fórmula propuesta pero no desarrollada por Norberto Chaves, 1990- suele ser reprimida por impertinente $y$, además, por cuanto puede llegar a poner en cuestión el saber del docente, aferrado a la cerrada ritualidad del "método".

Nuestra crítica a los métodos vigentes de enseñanza del Diseño no propone su erradicación, puesto que siguen siendo útiles en tanto garantizan la enseñabilidad de las disciplinas proyectuales, asegurando, dentro de ciertos límites, competencias y contextos institucionales, la eficaz "transmisión" de saberes y habilidades prácticas.

Lo que objetamos del método es su capacidad tanática para obturar la emergencia de nuevas alternativas de proyectación al priorizar, a la manera de la escolástica medieval, la repetición acrítica del saber consagrado impidiendo o, en el mejor de los casos, no estimulando la producción de investigaciones teóricas acerca del Diseño, sus modos de producción y de enseñanza. Cuestionamos el lugar que el método asigna al docente, que lo obliga, en la instancia de la "corrección", a reproducir su manera de diseñar formando alumnos-clones que aprenden "a su imagen y semejanza". Y cuestionamos sobre todo su tendencia a obliterar cualquier arresto experimentador que signifique abandonar el mullido mundo de las certezas para explorar el menos confortable, pero más estimulante territorio de la incertidumbre -que es lo experimental. Lo que criticamos es una praxis mutilada que muchas veces termina agotándose en rituales desprovistos de sentido y en productos anodinos.

Sólo resta agregar que la situación no es muy distinta en el área de la enseñanza de las Artes: Las academias han sido diseñadas para "transmitir" una formación básica y tienden a la inevitable uniformización de su alumnado para adaptarlos al rol social de "Profesor Superior" en tal o cual disciplina -que el Mercado y la sociedad demandan. El "talento" -si existe- implica transgresión productiva, es "peligroso" para su portador y para la comunidad organizada, no garantiza el "éxito" profesional, antes bien, suele atraer encono y sanción. El "talento", compleja estofa funcional, producto incontrolable del deseo inconsciente y sus imprevisibles tramitaciones sublimales, síntoma productivo de infrecuentes neurosis, no puede ser "transmitido" -por fortuna. Que de las Academias surjan "artistas" en sentido estricto, es una pura contingencia.

Enseñar a diseñar, enseñar Diseño o, mejor, diseñar diseñadores no puede limitarse a "enseñar" una metodología proyectual, que el alumno pueda hacer propia y utilizar con razonable eficacia. A esta formación, necesaria pero no suficiente, debemos incorporar algo de ese "salto al vacío" simbólico que lo experimental propone.

La institucionalización de espacios de experimentación en la enseñanza de los diseños, serviría, sin duda, para revitalizar los métodos convencionales. La experimentación, como síntesis de lo pulsional y 
de conciencia de lo pulsional, de lo sensible y de lo racional, del azar y del cálculo, es un camino todavía no explorado que vale la pena recorrer, allí donde el rigor no excluye al placer ni el trabajo al juego.

\section{Diseño, teoría y experimentación}

Cuando el Diseño -en sus múltiples especialidades: Gráfico, Industrial, de Indumentaria, Textil, de Imagen y Sonido, de Interiores, etc.- deja de ser el laborioso ejercicio de un oficio manual- muchas veces adquirido de manera autodidacta y no siempre considerado socialmente- para acceder al status universitario, es decir, cuando de la pura empiria el Diseño es constreñido a cierta episteme - lo ocurrido en Buenos Aires hace cerca de 20 años-, la nueva "disciplina" se ha ido instalando en el imaginario social -y en el imaginario de sus propios practicantes y docentesen un lugar incómodo: Ni ciencia, ni arte, ni -siquieratécnica, el Diseño habita en una suerte de limbo epistemológico del cual la módica producción "teórica" autóctona no ha logrado liberarlo. Algunos de los motivos de esta "falta de ser" de la disciplina ya fueron explicados en otro lugar, por lo que sería ocioso discutirlos nuevamente aquí (Valdés de León, 2001).

Para nosotros el Diseño - en el sentido más amplio del término- es una de las instancias, precisamente la del "proyecto", del proceso mediante el cual nuestra especie se ha ido apropiando del mundo material, esto es, de la "Naturaleza" - empezando por la propia- para explotarla en su beneficio mediante el trabajo socialmente organizado -en el seno de sociedades que van adoptando históricamente diferentes formaciones económicas y políticas en función del modo de producción dominante.

El Diseño, así entendido, ha desempeñado un rol protagónico en el devenir de la especie, en un largo y complicado itinerario que se inicia cuando ésta "inventa" la posición erecta - cuatro millones de años atrás - y fabrica las primeras herramientas - Homo habilis, hace dos millones y medio de años. Muy lentamente la especie se va despegando del resto de los primates superiores y de las ciegas determinaciones de la "Naturaleza", proceso para nada lineal ni "evolutivo" ni teleológico -como suele suponersesino, por el contrario, jalonado por una sucesión no programada de mutaciones y saltos cualitativos, muchos de ellos meros productos del azar, no exento de dramáticos fracasos -los "hombres" de Java, de Pekín, de Neanderthal, de CroM agnon y otros prototipos fallidos- proceso que culmina en el Homo sapiens sapiens, la actual especie dominante, que se ha ido diseñando a sí misma, modificando su propia "naturaleza" y la Naturaleza circundante, instaurando el reino de la Cultura mediante el trabajo, la ardua adquisición de la capacidad de simbolizar que cimenta el lenguaje y la vida en sociedad.

El Diseño -no como "disciplina" sino como inevitable y necesaria manera de ser del hombre en el mundo- protagoniza también los gigantescos logros de la Revolución Neolítica, la Primera Revolución Industrial: El control del fuego, la estabilización de la estructura parental -mediante el recurso del tabú del incesto-, la domesticación de especies animales inferiores, el abandono del nomadismo y la subsistencia por la caza y la recolección -la horda- por el sedentarismo -la tribu- y la agricultura, fruto del laborioso experimentar con especies vegetales silvestres hasta convertirlas en plantas alimenticias y proveedoras de insumos. En esta etapa se instalan los primeros poblados -luego ciudades-, se produce la invención de la escritura y la organización de sistemas de administración y distribución de los excedentes que dan origen a los primeros Estados históricos, en la Media Luna Fértil de Oriente Medio y en el Valle del Nilo.

Ya en la Modernidad el aporte del Diseño es innegable en el despliegue productivista de la Segunda Revolución Industrial: El aprovechamiento y manejo de nuevas fuentes de energía y de nuevos medios de transporte y comunicación -impulsados por máquinas de vapor-, la organización de la producción industrial de mercancías, el incremento exponencial de la urbanización, la irrupción de las "masas" en la vida política como consecuencia del incremento numérico y organizativo del proletariado, la instauración de la democracia representativa como forma generalizada de organización política -unida al surgimiento de los Estados nacionales- la construcción de consensos públicos y aparatos de control social con la invención de los medios "masivos" de comunicación y la moderna Publicidad. Cada uno de estos pasos ha sido también un acto de diseño. En tanto ser hablante el hombre es, por eso mismo, un ser que diseña, puesto que la condición humana es la de un ser lanzado al futuro que sólo se realiza en la tensión de proyectar porvenires posibles y, en algunas ocasiones, también imposibles.

En el sentido moderno del término, el Diseño es, pues, causa y consecuencia de la complejidad creciente de los aparatos del Estado, de la economía capitalista y de las tecnologías de producción, que imponen una también creciente división social del trabajo, la escisión tajante e irreversible entre la instancia del "proyecto" y la de "producción industrial" y la consiguiente especialización de saberes y habilidades. Los efectos traumáticos de esta Spaltung, tanto en el orden social como en el subjetivo, fueron descritos por Karl Marx en su investigación sobre la enajenación en el trabajo, aún vigente. (Marx y Engels, 1848, 1932, 1993 y, tangencialmente, por Sigmund Freud, 1930,1998)

En el marco de esta conceptualización, sumamente amplia, en un sentido más técnico y operativo, el Diseño puede ser redefinido como una práctica social especializada que consiste en el procesamiento racional, intuitivo y fáctico de una serie de variables objetivas y subjetivas por medio del cual los hombres intervienen operativamente sobre la realidad material, "natural" y artificial, para producir -siguiendo una metodología proyectual y en el interior de un horizonte tecnológico, estético e ideológico predeterminado- objetos, servicios y mensajes des-tinados a satisfacer las demandas, reales o inducidas, mate- 
riales y simbólicas de un Mercado segmentado en estratos económicos y socio gráficos -en condiciones tales que garantice un razonable beneficio económico al productor-; todo ello dentro de un contexto histórico y cultural dado. El momento clave de este proceso está fincado en la etapa de proyectación o prefiguración, sobre la que volveremos más adelante. Con la intervención del Diseño que, como ya fue dicho, se concreta merced a la división y organización del trabajo, el entorno físico y simbólico -el "medio ambiente" - será modificado, en general de manera traumática- el motor a explosión y el automóvil- y para peor, en muchas ocasiones, de manera irreversible - el "efecto invernadero".

Resulta entonces ingenuo sostener que los diseñadores -ese amplio colectivo que incluye, en incómoda fraternidad, desde los arquitectos, a pesar de la fatua solemnidad que algunos de ellos ostentan, hasta los diseñadores de "modas", pese al estudiado estilo casual de algunos de sus practicantes-, sería ingenuo sostener, repetimos, que los diseñadores se limitan simplemente a diseñar "objetos" de diferentes dimensiones y complejidad, como muchos todavía creen: Lo que en verdad diseñan -a veces sin tener conciencia de ello- son comportamientos, conductas y creencias, modelando subjetividades, modos de ver y de ser, consensos, entornos, en fin, ideología: Al tiempo que incorporan un importante valor agregado, simbólico, a los objetos que diseñan.

En efecto -y está inscripto en la palabra mismadiseñar es transmutar la materia en signo, esto es, designar, otorgar sentido al objeto -mediante un gesto, el designio, no exento de voluntarismointegrándolo al mundo de la cultura, que no es otra cosa que la construcción y reproducción de símbolos socialmente compartidos. Es en este proceso, de carácter industrial, que el objeto diseñado, puesto en signo, agrega a su primario valor de uso un nuevo valor -de cambio-, desplazamiento productor de plusvalía-motor "inmóvil" de la acumulación de capital. En ese sentido afirmamos que la "función" última del Diseño consiste en contribuir, en tanto insumo, a la reproducción de las condiciones materiales y simbólicas de la existencia de los hombres en sociedad, en el interior del modo capitalista de producción: la "función" real del Diseño es, pues, del orden de la economía, tal como sostuvimos en nuestra intervención en la Universidad Autónoma de Nuevo León, México (UANL, Noticias 2002).

\section{Acerca de la prefiguración}

En su oportunidad (Valdés de León, 1995) hemos establecido las condiciones necesarias que distinguen el acto de Diseñar: Pre-figuración, utilidad, forma, significación y rentabilidad. A los fines de la indagación que venimos intentando es oportuno revistar la primera de dichas condiciones.

Al respecto observamos que el Diseño, en su práctica, "experimenta" o padece, según se mire, una pro- funda contradicción. Por un lado, en su instancia intuitiva o "creativa", esto es, en el momento de proyectar -en el cual ya está "presente" en el imaginario del diseñador aquello que, en la realidad, sólo alcanzará entidad material en un futuro hipotéticoel Diseño pre-figura -a eso está designado- objetos o servicios o mensajes- que no existen, salvo como pura potencialidad, al momento de iniciarse el proceso de diseño. Por esta vertiente, si se quiere "creacionista", el acto de diseñar se emparienta con las artes, si bien sus condicionamientos externos son mucho más imperativos, cuando no inexorables.

Pero, por otro lado -y aquí irrumpe la contradicción apuntada- los tiempos reales en los cuales la demanda del comitente debe ser satisfecha, el presupuesto disponible, las limitaciones tecnológicas, las tendencias estéticas y dominantes -y hasta el "gusto" personal del comitente o de su mujer- son algunos, entre muchos otros, factores que impiden que la instancia de búsqueda de soluciones innovadoras, mediante la experimentación, pueda ser explorada exhaustivamente. La "tiranía del tiempo", que no es otra que la tiranía del Mercado, imposibilita -0, en el mejor de los casos, dificulta- el ejercicio experimental, ínsito en el ser del Diseño.

Por lo demás ya es sabido -aunque esta verdad siga siendo pudorosamente velada- que el Diseño no necesariamente produce objetos y servicios "útiles al hombre" -nada ingenua falacia aún sin demoler. Y esto es así por cuanto el Diseño no es un factor autónomo en el proceso productivo: En tanto servicio, el diseñado "producirá" aquello que el Mercado le demande. Pero además, y como contrapartida, el objetivo de las empresas e instituciones, usuarias primarias del Diseño, no es tampoco producir objetos "útiles al hombre", con menos solemnidad y más espíritu práctico, su objetivo es producir mercancías que generen un razonable beneficio económico, puesto que su legítima razón de ser en el interior del modo de producción no es otro que el lucro será en todo caso tarea del "creativo" publicitario y de los medios masivos de comunicación que los productos, cualquiera fuere su utilidad "real", terminen siendo percibidos por los consumidores como "necesarios", cuando no como "indispensables": "En junio -publica el diario Clarín- motorizado por el Día del Padre, se vendieron 340.000 nuevos aparatos" -refiriéndose a celulares cuyo precio oscilaba de ciento sesenta a mil seiscientos pesos (Diario Clarín, 13 de julio 2002). Esto no garantiza trescientos cuarenta mil padres más felices, pero sí aseguró jugosos beneficios a los fabricantes y vendedores.

Si a esta descripción, que pretende ser objetiva, agregamos que tanto la práctica de Diseño como su enseñanza en los claustros universitarios -como ya puntualizamos- están regidos por un método que inhibe - 0 , en todo caso, no estimula- la emergencia de la "ocurrencia", resquicio mediante el cual el pensamiento creativo, poético, puede deslizar su insolencia -se llega a la conclusión, poco alentadora, de que la primigenia vocación innovadora y experi- 
mental del Diseño termina, casi siempre, sofocada, esto es, reprimida -con toda la carga freudiana del término- en la cauta cotidianeidad de su práctica -y de su enseñanza.

\section{Ampliando el horizonte de lo posible}

Ahora bien, esta imposibilidad, ¿Es una consecuencia del "orden natural de las cosas", de una ciega ley a la que el Diseño está sujeto de manera inexorable? ¿O sólo se trata de un síntoma, producto de determinada coyuntura social?

Por fortuna, la historia del Diseño - que, como hemos visto excede con largueza a la "Historia" convencional, que comienza a partir de la invención de la escritura - da cuenta de momentos en los cuales el Diseño, en función de circunstancias históricas excepcionales, logró desplegar su formidable potencial creativo y experimental.

Quizá la más significativa de estas eclosiones se produjo entre 1917 y 1930, paradójicamente, en uno de los países más atrasados de Europa. Nos referimos al conjunto de movimientos políticos, artísticos y culturales que confluyeron, al calor de los primeros años de la Revolución Bolchevique, en el denominado "Constructivismo Soviético", la convergencia de las vanguardias artísticas -en especial, el Futurismo y el Suprematismo- y la vanguardia política dio por resultado cambios revolucionarios de entender las relaciones entre el Arte y la vida, entre los artistas y la sociedad. Por su relevancia en orden a sus aportes teóricos y práctica intensiva de la experimentación, el Constructivismo será desarrollado, por separado, en un futuro trabajo.

Algo semejante ocurrió, aunque en escala mucho menor, en el México revolucionario, entre 1910 y 1934 con la emergencia del Muralismo (José Clemente Orozco, Diego Rivera y David Alfaro Siqueiros, a partir de las ideas de Gerardo Murillo, el "Doctor Atl" ) y su propuesta de un arte público y fuertemente politizado, que no es más que una de las expresiones, la más conocida, de un movimiento mucho más amplio en las artes y la cultura: Rufino Tamayo, Tina Modotti, Frida Kahlo, Manuel Ponce, Carlos Chávez, Silvestre Revueltas, Mariano Azuela (Los de Abajo), Alfonso Reyes y otros.

Al mismo tiempo, pero en la (malograda) República de Weimar surge el movimiento de la Nueva Objetividad (Neue Sachlichkeit) que entre 1919 y 1933 produce una formidable obra plástica y gráfica (Georg Schulz, M ax Beckman, Otto Dix) que denuncia el sistema social vigente y el vertiginoso ascenso del nazismo; el sector más radicalizado funda en 1924 el Grupo Rojo (Rote Grupe) integrado por Georg Grosz, Rudolf Schlichter y John Heartfiel (Helmut Herzfelde). Este movimiento también conocido en la época con el nombre de "realismo mágico" - el término fue acuñado por el crítico Franz Roh en 1924 -transcurre en un clima de gran agitación política y experimentación artística: Robert Wiene, Fritz Lang, Bertolt Brecht, Erwin Piscator -y no ha disfrutado por parte de la crítica, seguramente por su radicalismo, de la consideración que sí ha dispensado, a veces con exceso, a su contemporánea pero políticamente acomodaticia, Bauhaus.

\section{La experimentación en la enseñanza del Diseño}

Que la experimentación en las artes y el Diseño aparezca vinculada a grandes transformaciones sociales y políticas -como ocurrió en Argentina entre los años 60' y 70' pasados- no significa en absoluto que en una escala muchísimo más modesta, en el ámbito especializado de la enseñanza de las disciplinas proyectuales, la experimentación no sea posible. Además de posible, la experimentación resulta imprescindible, al menos en el área de la enseñanza del Diseño -que es la que nos ocupa- como estrategia para evitar que la inevitable racionalidad del método termine por convertirla en mera "fórmula", en ejercicio monótono y previsible más cerca del ritual que del descubrimiento.

En su función de " diseñar diseñadores, la enseñanza de las disciplinas proyectuales nos proporciona un espacio privilegiado para la experimentación: Aquel que transcurre desde el momento en que el docente establece -mediante una serie de enunciados- la consigna del proyecto hasta que éste es realizado por el alumno -mediante una determinada enunciación visual. La sucesión de bocetos es la huella -en sentido peirciano- del camino a caminos recorridos por el alumno, trayecto necesariamente experimental. El docente conoce de antemano qué saberes debe construir el alumno de cuya formación es responsable y cuenta para ello con programas de contenidos racionalmente redactados, apoyo visual y audiovisual, determinada bibliografía y una serie escalonada de Trabajos Prácticos, el docente sabe acerca de su "producto".

Pero no sabe -o no debería saber- que "productos" va a realizar cada alumno en particular, cada sujeto, a lo largo del proceso; allí es donde se abre, precisamente, un espacio disponible para la innovación, para la emergencia del sujeto y la transgresión poética. Ahora bien, la subjetividad -potencialmente creativadel alumno, podrá emerger, sí y sólo sí, el docente deniega del sitial imaginario de Sujeto supuesto saber, tras del cual suele abroquelarse y asuma -lo que no siempre es tolerable- el rol menos narcisista, pero mucho más fructífero, de Sujeto dispuesto al saber al "saber" del otro, el sujeto del aprendizaje.

En este sentido, la "ignorancia" estructural del docente con respecto al "producto" del alumno es fundamental para promover su autonomía, para que en algún momento éste pueda autorizarse a sí mismo como diseñador.

Todo esto no significa, en absoluto, que el docente no deba "impartir" y hasta imponer al alumno el conocimiento de los procedimientos metodológicos y técnicos adecuados al proyecto -las todavía llamadas "reglas del arte" - y cuya incorporación por el alumno deberá verificar. Pero sí lo obliga, también de manera absoluta, a abstenerse de imponer, sea por inducción, sea por coerción, su particular manera de practicar y 
entender el Diseño, en especial en la instancia crucial de la "corrección" -en el estilo "esto se hace asi", como si existiera una única manera, la "correcta" , de resolver un problema de diseño.

Esta práctica, la de imponer un modelo, nos retrotrae a la arcaica escena del "Taller" Medieval -anacrónicamente "reciclada" por la Bauhaus en 1918- en el cual el "maestro", depositario absoluto del Saber -y del poder- se impone autoritariamente como "modelo" a través de la estructura jerárquica de los "Oficiales", a los "aprendices" -ontológicamente ignorantes- quienes deben absorber sin chistar aquel "saber" mediante la reproducción y copia del modelo -so pena de ser "reprobados". (cualquier parecido con cierta institución pública de enseñanza de Diseño no es coincidencia) Resulta llamativo que el término "Taller", con sus connotaciones de manualidad, repetición u copia se siga utilizando todavía en el ámbito académico, quizá por mero efecto de inercia. Fuera de cualquier regresión medievalista, el docente puede producir alumnos "creativos" -sin entrar por ahora a discutir el término- en la medida en que sea capaz de producir en el aula determinadas condiciones ecológicas que propicien la experimentación. Es obvio que ante propuestas inviables por parte alumno, el docente intervendrá activamente, explicando porqué aquellas son erróneas o inconsistentes, pero sus indicaciones deberán ser lo más genéricas posible, dejando siempre en el alumno la toma de decisiones, tratando de evitar que éste caiga en la trampa del estereotipo.

El docente debe aceptar que no tiene, ni puede tener, ni es deseable que tenga, todas las "respuestas" operativas que el alumno le demanda -puesto que tales "respuestas", si en efecto existen, las debe encontrar o construir el alumno desde su propio imaginario. En la práctica es más que probable que el docente, según su experiencia y su sensibilidad, ya disponga, en efecto, de una "respuesta" adecuada al problema de diseño planteado, pero entonces, un imperativo ético, consubstancial a la función docente, le impondrá abstenerse se "sugerir" dicha solución, por el contrario, su tarea será la de estimular en el alumno la producción de asociaciones que, con mucha probabilidad, lo incitarán a proponer soluciones propias, y como tales, más productivas.

El acto de "corregir", en este contexto, adquiere un nuevo sentido, el de co-regir, esto es, de acuerdo a la segunda acepción del término, "conducir", o si se prefiere, acompañar al alumno en su búsqueda, mostrando y abriendo, según su capacidad, caminos aún no transitados; avalando, inclusive, la transgresión de las reglas -no así su desconocimientocuando ésta devenga productiva. Este proceder no hace sino problematizar la cuestión de la evaluación - ¿Proceso o producto?- que no será abordada en este ensayo.

En realidad, no estamos diciendo nada nuevo: La mayéutica, junto con la ironía, eran los recursos que Sócrates utilizaba para "descubrir" la verdad en el otro, para que el otro accediera a su verdad, hace más de 2500 años.

\section{El docente como sujeto dispuesto al saber}

El Diseño y la Comunicación son fenómenos sociales sumamente complejos cuyo modo de ser es el cambio -y no nos referimos sólo a las innovaciones tecnológicas- en tanto prácticas que se producen en el interior de sociedades atravesadas por procesos-tecnoeconómicos, políticos, culturales- de transformación. De la misma manera, las teorías que a lo largo de la historia han intentado dar cuenta de tales fenómenos (en el caso de los signos, a título de ejemplo, desde San Agustín y Guillermo de Occam hasta Naomi Klein) se han ido decantando y modificando conforme el objeto de estudio se desplaza y complejiza.

En lo que respecta a la enseñanza de estas disciplinas, por lo tanto, el docente debe estar dispuesto a mirar críticamente su saber teórico -así como las técnicas que utiliza para su "transmisión" - en la medida en que la realidad objetiva del contexto y de su propia práctica le señalen el riesgo de desajustes: El docente tiene que estar dispuesto al saber, a la permanente actualización de sus conocimientos acerca de la disciplina y la investigación y a la puesta en crisis de sus supuestos teóricos.

En ese sentido, es preocupante que todavía se siga repitiendo como "explicación" definitiva del proceso de la comunicación social el vetusto esquema “ ¡ Emisor Receptor!", en una versión reduccionista de la Teoría M atemática de la Información (Shannon, C, y Weaver, W., 1949/1981). Aunque los autores describen con toda claridad que el "emisor" y el "receptor" designan a los artefactos técnicos -micrófono y auricular respectivamente- que permiten la conversión de la voz en oscilaciones eléctricas y su posterior reconversión para que el mensaje verbal de la Fuente llegue con la mayor fidelidad posible al destino, sus divulgadores han distorsionado grave-mente este esquema hasta hacerlo irreconocible, convirtiendo a los que eran simples artefactos téc-nicos en los actores del acto comunicacional ("Emisor - Mensaje -" Receptor") imponiéndolo merced a su constante repetición como el modelo universal de la comunicación sin percatarse de su tosco biologismo, derivado de la relación causal "estímulo-respuesta". Sin mencionar, en el campo de la "gráfica" y la Publicidad la incesante referencia a supuestos "ruidos visuales", concepto sacado del contexto de la teoría e hipostasiado hasta la exasperación y el disparate. La hegemonía del esquema "Emisor - Receptor" es un claro ejemplo de la "resistencia" a desprenderse a un saber coagulado -que no resiste su confrontación con la práctica- y que desconoce los avatares que las teorías de la Comunicación, han recorrido desde Mijail Bajtin (Qué es el lenguaje, 1929/1998) y Karl Bülher (Teoría del lenguaje, 1934), pasando por Norbert Wiener (1948), Roman Jakobson, D. Hymes y J.J. Gumperz, D.Anzieu, B. Rimé y P. Watzlawick hasta Noam Chomsky $(1965,1970)$ y Jürgen Habermas (1981). Arduo recorrido que por lo demás está al alcance de cualquiera en los textos de Edmond Marc y Dominique Picard (1983/1992), de Armand y Michélle Mattelart (1991/1997) o de Christian Baylon y Xavier Mignot (1994/1996). 
Nuestra objeción a aquel saber cosificado no se reduce a una mera cuestión terminológica -aunque esta no es irrelevante- sino a las consecuencias prácticas que tal saber entraña: Tras la inocente fachada discursiva del esquema E-R, casi "naturalizado" a fuerza de repetirlo, se vislumbra la imagen de un gran "Emisor" que propala ("Emite" en la jerga usual) un discurso único ante una multitud de anónimos "receptores" que obedientes incorporan pasivamente ese discurso como la verdad indiscutible. (ver Yo, robot, de Alex Proyas, 2004)

Ya en el siglo XIX el lógico y matemático Charles Lutwidge Dodgson había imaginado este siniestro "emisor" en la ficción de $A$ través del espejo y lo que Alicia encontró allí (Trough The Looking Glass And What Alice Found There, 1871/1999), publicado con el seudónimo de Lewis Carrol.

La escena es bien conocida: Ante el uso, sólo en apariencia arbitrario que Humpty-Dumpty -sólo en apariencia necio- hace de las palabras del lenguaje, Alicia protesta acaloradamente:

- Pero "gloria" no significa "argumento contundente" -objetó Alicia.

-Cuando yo empleo una palabra -dijo HupmtyDumpty en tono despectivo- significa exactamente lo que yo quiero que signifique: Ni más ni menos.

- La cuestión es -dijo Alicia- si puede hacer usted que las palabras signifiquen tantas cosas diferentes.

- La cuestión es quién manda -dijo Hunpty Dumpty-: Nada más.

Aunque las intenciones pedagógicas del reverendo Dodgson eran seguramente otras, este diálogo desnuda con claridad la estrecha relación que liga al lenguaje con el poder: El diálogo, en efecto, pone en escena la lógica y la efectividad de un lenguaje de clase (Hierro S. Pescador, J., 1984), el de la clase dominante, mediante el cual ésta impone sus valores a las clases dominadas y al conjunto de la sociedad civil, que las incorpora como "propios" -operación que fuera estudiada por Antonio Gramsci con la denominación de "hegemonía" (Gramsci, Antonio, 1929/1935,1984)

El desagradable y ominoso personaje de Lewis Carrol resulta una poética premonición del rol que en la actualidad desempeñan los medios masivos de comunicación en la conformación ideológica de la llamada "opinión pública" -y preanuncia a ese Gran "Emisor" omnipotente que encarga George W. Bush con su discurso maniqueo y mesiánico.

\section{Una confusión semántica}

Una consideración final, de orden más técnico, amerita la extendida equivocidad que se percibe en el uso que se hace de las categorías de "signo lingüístico" y "signos visuales", pura entidad psíquica el primero, evidente materialidad perceptible el segundo- y a pesar de que cada uno de ellos remita a registros sensoriales diferentes e incompatibles. Aunque tanto Ferdinand de Saussure (1916/1994) como Charlos S.Peirce (1931-1935) parten de distintos presupuestos epistemológicos y aunque sus ideas han sido formuladas con toda precisión en sus respectivos textos, en la instancia de su "transmisión" y de su "aplicación" a la práctica del Diseño, aquellas diferencias quedan anuladas y confundidas en una mezcolanza ecléctica e indiscriminada. Eclecticismo que se agrava cuando a este conglomerado se superponen, acríticamente, las conocidas categorías semióticas de Charles Morris (1938) -semántica, sintáctica y pragmática-, términos como "ruido visual", ya comentado, o "refuerzo semántico", ilustran esta confusión. Las categorías semióticas mencionadas sólo tienen sentido en una teoría general del signo, pero son inaplicables al análisis del signo lingüístico -y del lenguaje como tal- para el cual Saussure y sus seguidores (Martinet, pero también Chomsky) han establecido un conjunto específico de categorías (Significante/Significado, Paradigma/Sintagma, Lengua/Habla -o Competencia/Actuación-, M orfemas - o Monemas-/Fonemas) que, a la vez, no pueden ser trasladados abusivamente al análisis del signo en general, por su carácter específicamente lingüístico. Como se ve, se trata de conjuntos teóricos que en Matemática se denominan sistemas incompatibles, y en la terminología de Khun, paradigmas inconmensurables.

No se trata, de nuevo, de una bizantina discusión "semántica" sino de las consecuencias más generales de tal desplazamiento, mediante el cual se obvia la irreductible diferencia, filosófica y epistemológica, mutuamente excluyente, que por fortuna distingue el enfoque estructuralista del pensamiento de Saussure -que ha posibilitado relacionarlo con el marxismo y con el psicoanálisis freudiano, en particular en su vertiente lacaniana- y la posición funcional-conductista de los autores norteamericanos, inspirados en el "behaviorismo" de John B. Watson por un lado y en el pragmatismo filosófico de William James y John Dewey, por el otro.

Además de ser la expresión de opuestas "concepciones del mundo", desde la epistemología aquella "diferencia" se manifiesta en la distinción disciplinar entre la Semiología, atenta a las determinaciones sociales de los signos -como una rama de la Psicología Social- y la Semiótica, interesada exclusivamente en las cuestiones lógicas, instrumentales y utilitarias. Al César lo que es del César...

Problematizar estas cuestiones que hacen estrictamente a la función docente resulta por demás pertinente a nuestro empeño, puesto que en tanto persistan restos de saberes fosilizados en nuestro discurso, estaremos obturando la producción de conocimientos nuevos y la posibilidad misma de la experimentación, puesta en juego de la creatividad virtud que, bien entendida,- debe empezar por darse en la propia práctica docente: No es posible dar, ni exigir del otro, aquello de lo cual se carece.

\section{Se hace camino al andar...}

A lo largo de este ensayo -en sí mismo una "experiencia" - hemos intentado trazar un cierto itinerario, entre otros que también pudieron haber sido, de los avatares de la experimentación, como herramienta clave para poder ampliar, tensionándolo, el horizonte 
de lo posible, como utopía realizable.

Retornamos entonces a nuestro punto de partida las posibilidades realmente existentes de experimentar en el campo del Diseño y en su enseñanza en las circunstancias concretas del aquí y ahora. (Valdés de León, 2004).

Podemos, por lo tanto, proponer algunas conclusiones. Alcanzar y mantener una posición de liderazgo en el área especializada -y conflictiva- de la enseñanza de las disciplinas proyectuales presupone, como condiciones necesarias, la existencia de una eficiente infraestructura material y operativa, una sólida trayectoria institucional, equipos experimentados y actualizados de docentes, objetivos claros, voluntad de liderazgo y proyectos innovadores.

Entendemos que estas condiciones, en términos generales existen en nuestra Facultad y es en la última de ellas donde la experimentación deberá desplegarse más vigorosamente, en diferentes instancias y con objetivos específicos.

\section{La experimentación en el aula}

Es la que se efectiviza en la etapa de corrección de los trabajos prácticos. Entendemos que en esta instancia la práctica de la experimentación exige ser profundizada, toda vez que su potencialidad creativa y productivista no ha sido explorada a fondo, como consecuencia de las resistencias y limitaciones examinadas en el capítulo anterior.

\section{La experimentación en los fundamentos: La Investigación}

La agenda de las cuestiones sin resolver en orden a los fundamentos teóricos y epistemológicos de las disciplinas proyectuales es amplia y variada -como lo demuestran los ejemplos antes expuestos. Cuestiones básicas que hacen al abordaje científico de una disciplina, tales como la delimitación estricta del objeto de estudio, la elaboración de una Teoría General del Diseño, el establecimiento de una terminología clara y precisa de una metodología específica (Siegfried Maser, 1972, citado por Burdek, Bernhard E., 1994) aún están pendientes y exigen ser discutidas con el rigor académico que merecen.

El debate transdisciplinar, la investigación sobre temáticas puntuales, la realización regular de seminarios de actualización, la promoción de estudios de casos y la publicación y divulgación de aquellos trabajos cuyos aportes así lo ameriten, son algunas de las vías idóneas para la construcción de una nueva tradición teórica e historiográfica superadora del árido paisaje discursivo que nos rodea, o si se quiere, para la construcción de un nuevo paradigma.

\section{Laboratorio experimental}

El Laboratorio surge como una respuesta institucional a los factores y determinaciones externas que impiden o dificultan la experimentación en el Diseño. Como todo laboratorio es un espacio artificial en cuyo interior, por períodos de tiempo preestablecidos, quedan en suspenso, provisionalmente, aquellos factores y determinaciones, creándose las condiciones adecuadas para que docentes y alumnos puedan experimentar sobre la base de proyectos sustentables.

El arco de posibilidades no es excluyente: Desde experiencias puramente formales sobre la materia hasta programas de Diseño de proyección social. En mérito a esa amplitud nos limitaremos a esbozar algunas líneas de trabajo.

1- Experimento con materiales no convencionales y reciclado de material de desecho.

2- Investigación de demandas sociales, existentes 0 potenciales, que no son consideradas por el Mercado, por estimarlas de baja rentabilidad. Diseño de aquellos productos que, eventualmente, podrían satisfacer tales demandas.

3- Investigación y formulación de demandas no presentes en la actualidad pero previsibles en el futuro próximo; por esta vía la experimentación deviene prospectiva y anticipación.

4- Proyectos de diseño de objetos aún no existentes, capaces de generar nuevos usuarios o nuevas modalidades de uso.

5- Propuesta y puesta en práctica de métodos de enseñanza no tradicionales, que superen la escolástica reinante.

6- Proyectos de investigación que impliquen la interrelación de las disciplinas proyectuales entre sí, y la de éstas con las disciplinas no proyectuales -y contribuyan a disolver compartimentos estancos y promuevan la socialización del conocimiento.

La lista podría ser interminable.

Como se ve, imaginamos el Laboratorio Experimental como un espacio de interacción productiva de saberes, técnicas y disciplinas diferentes, pero convergemos todas en el objetivo de generar cambios cualitativos en el Diseño -y en su enseñanza. Un espacio para imaginar y diseñar nuevos escenarios objetuales, visuales y comunicacionales- apto para el despliegue fluido del pensamiento creativo y, a la vez, sensible a las demandas de la realidad.

Esperamos, por último que del Laboratorio puedan surgir, además de respuestas innovadoras, preguntas aún no formuladas -y la búsqueda de nuevas respuestas a esas preguntas, en un movimiento que, como la vida misma, nunca cesa en su empuje. 


\section{Epílogo}

La improvisación y la repetición son la muerte del Arte -nos advierte una placa desde las paredes del Teatro Colón: La experimentación sistemática, fundada sobre sólidos presupuestos teóricos, puesta en obra a través de proyectos sustentables pero abiertos a la inclusión de lo lúdico, con objetivos prácticos de utilidad social pero no estrechamente mercantilistas, es para quienes hemos elegido el Diseño como forma de vida, una manera de superar

\section{Bibliografía}

- Bajtin, Mijail (1929) Chtó takoie iaizk. Publicado bajo el nombre de V. N. Voloshinov en Literaturnaia uchava. Leningrado. (1998) ¿Qué es el lenguaje? Buenos Aires: Almagesto.

- Baylón, Ch., Mignot, X. (1994) La communication. Paris. Nathan. (1996) La comunicación. Madrid: Cátedra.

- Bühler, Kart (1934) Teoría del lenguaje.

- Bunge, Mario (1989) La investigación científica. Su estrategia y su filosofía. Barcelona: Ariel.

- Bürdek, Bernhard E. (1991) Design. Geschichte,Theorie und Praxis der Produkgestaltung. Colonia. DuM ont.

- Buchverlang GmbH \& Co. Kommand digesellschaft. (1999) Diseño. Historia, teoría ypráctica del Diseño In dustrial. Barcelona: Gustavo Gili.

- Carrol, Lewis

(1999) A través del espejo y lo que Alicia encontró allí. Madrid. Akal (pag.252) Se mantuvo el nombre del personaje en su versión original.

(1871) Trough the Looking-Glass and what Alice Found There. Londres: Macmillan.

- Chaves, Norberto (1990) La imagen corporativa. Teoría y método de la identificación visual, Barcelona: Gustavo Gill.

- Capanna, Pablo (2004, marzo 6) La industria de la ciencia. En suplemento Futuro, Página 12.

- Chomsky, Noam (1965) Aspects of the Theory of Sintax.

- Cambridge. MIT Press. (1970) Aspectos de la teoría de la sintaxis. Madrid: Aguilar.

- Clarín (2004, julio 13)

- Costa, Joan.

(1988) La imagen global. Barcelona CEAC.de Morgan, August.

(1847) Lógica formal o el cálculo de la inferencia.

- Freud, Sigmund (1900) Die Traumdeutung. Leipzig y Viena.

- Fritz Deuticke.

(1995) Pulsión y destinos de pulsión. Obras completas. Tomo 14. Buenos Aires: Amorrortu.

(1989) La interpretación de los sueños. Obras Completas tomos 4 y 5 . Buenos Aires: Amorrortu.

Trieb und Triebshicksale. Leipzig y Viena. Int. Z. arzatl Psychonalyscher, 3, n으.

(1930) Die Unbehagen. Leipzig, Viena y Zurich.

Internationaler Psycho-analytischer Verlang. (1998)

El malestar en la cultura. Obras completas. Tomo 21. Buenos Aires: Amorrortu. (Nota al pie, pág.80.)

- Gramsci, Antonio 1929-1935.

(1998) Cartas desde la cárcel. Buenos Aires: Nueva Visión.

(1971) Selection from the Prison Notebooks. Londres: Lawrence \& Wishart.

- Habermas, Jürgen.

(1988) Teoría de la acción comunicativa. Madrid: Tau aquel dilema al incorporar a la práctica del oficio y a la reflexión sobre esta práctica la alquimia de la poiesis. Si aceptamos como cierto que la poesía es un arma cargada de futuro (Gabriel Celaya) coincidiremos también en que por la vía de la experimentación podemos acechar y, tal vez, contribuir desde la disciplina a la construcción de un mundo más humano. o por lo menos, más habitable.

rus. Hierro S. Pescador, José

(1984) Principios de Filosofía del lenguaje. 1. Teoría de los signos. Teoría de la gramática. Epistemología del Lenguaje. Madrid: Alianza.

(1981) Teorie des Kommunikation Handeln. Frankfurt: Suhrkamp.

- Hobsbawn, Eric.

(1999) A la zaga. Decadencia y fracaso de las vanguardias del siglo XX. Barcelona: Crítica.

(1998) Behind the Times: The Decline and Fall of the Twentieth-Century Avant Gardes.

- Lucie-Smith, Edward.

(2000) Artes visuales en el siglo XX. Colonia:

Verlagsgesellschaft mbm.

(1996) Visual Arts in the Twentieth Century. Londres: Lawrence King Publishing.

- Marc. E., Picard, D.

(1992) La interacción social. Cultura, instituciones y comunicación. Barcelona: Paidós.

(1983) L'interaction sociale. Paris.

- Marx, Karl., Engels, Friedrich

(1993) Manuscritos: economía y filosofía. Barcelona:

Altaya.

(1932) Marx Engels Gesamte Ausgabe. Sec. I Vol. 3.

Berlín.

- Mattelart, Armand, Mattelart, Michéle.

(1997) Historia de las teorías de la comunicación.

Barcelona: Paidós.

(1995) Histoire des théories de la communication. París: La Découvert.

- Morris, Charles.

(1958) Fundamentos de las teorías de los signos.

México. Universidad Nacional de México.

(1938) Foundation on the Theory of Signs. Chicago: University of Chicago Press.

- Muñoz, Blanca (1989) Cultura y comunicación. Introducción a las teorías contemporáneas. Barcelona: Barcanova.

- Peirce, Charles (1930-1958) Collected Papers. Harvard: University Press.

- Popper, Karl 1934.

(2001) La lógica de la investigación científica. Madrid: Tecnos.

(1937) The Logic of Scientific Discovery. Nueva York: Harper and Row.

- Saussure, Ferdinand de.

(1994) Curso de ligüística general. Madrid: Alianza.

(1916) Cours de linguistique générale. Paris: Payot.

- Shannon, C., Weaver, W.

(1981) Teoría Matemática de la Comunicación. Madrid: Forja. 
(1949) The Mathematical Theory of communication. Urbana-Champaing III- University of Illinois.

- UANL Universidad Autónoma de Nuevo León. (2002, noviembre 22) Noticias. Versión electrónica. webmaster@vanl.mx Valdés de León, G. A.

(2004) Acerca de la posibilidad de experimentación en Diseño, en diseño \& comunicación. Bs. As. Universidad de Palermo.

(2003) La cultura "popular" en la Modernidad europea. De la unidad a la escisión: transición y re-significación. (inédito) Buenos Aires: Facultad de Humanidades.

Universidad de Palermo.

(2001) M iseria de la teoría, en Cuaderno no 2, Proyectos en el Aula. Buenos Aires: Facultad de Diseño y Comuni- cación. Universidad de Palermo.

(1995) Contribución para una epistemología del "Diseño gráfico", en Otro diseño es posible. Cátedra G. Valdés. Buenos Aires: Facultad de Arquitectura, Diseño y Urbanismo.Universidad Nacional de Buenos Aires.

- Varsavsky, Oscar (1975) Ciencia, política y cientificismo. Buenos Aires: Centro Editor de América Latina.

Whitford, Frank.

(1991) La Bauhaus. Barcelona: Destino.

(1984) Bauhaus. Londres. Thames and Hudson.

- Wiener, Norbert (1948) Cybernetics or Control and Communication in the Animal and the Machine. Nueva York. -Wiley. (1985) Cibernética o control y comunicación en animales y máquinas. Barcelona: Tusquets. 